\title{
Special Issue: Logistics Systems Design in Latin America
}

\author{
Miguel Gastón Cedillo-Campos ${ }^{1}(\mathbb{D})$, Juan Carlos Villa ${ }^{2}$ \\ ${ }^{1}$ National Laboratory for Transportation Systems and Logistics, Mexican Institute of Transportation (Mexico) \\ ${ }^{2}$ Texas A\&M Transportation Institute (United States) \\ gaston.cedillo@imt.mx,_L-Villa@,tti.tamu.edu
}

Received: March 2017

Accepted: October 2017

\section{Introduction}

Logistics systems have a strategic importance for Latin American competitiveness. During the last decades, geographical dispersion of industrial and service processes supported by logistics progresses allowed Latin American companies to be part of the global value chains (Blyde et al., 2014). In fact, the offshoring strategies are an important strategy of most of the modern manufacturing business models located in the region (Cedillo-Campos et al. 2014; Anderson and Villa, 2015). However, the Inter-American Development Bank estimates that logistics costs in Latin America and the Caribbean can be between 50 and 100 percent higher than in the Organization for Economic Co-operation and Development countries (IDB, 2017). Additionally, most of the Latin American export-oriented companies deliver products to a limited number of markets, making them commercially dependent.

Economic difficulties in the Latin American region and the increasing protectionism and nationalism in some developed countries have led to uncertainty and greater interest to develop regional markets and to strengthen a more diverse market base. (The Economist, 2016; Capurro, 2017). Nevertheless, diversifying markets implies longer transit times and dealing with administrative procedures that bring inefficiency to the supply chains. Therefore, a better and deeper knowledge of logistics in the region is nowadays required to control landed costs and make more efficient logistics systems.

Moreover, the high rate of urbanization in Latin American countries, which is approximately of 80 percent (BBVA Research, 2017), is generating important challenges such as distributions of goods and 
movements of people in urban areas. This is requiring better routing schemes. In fact, higher population density in urban areas is creating traffic congestion that reduces logistics fluidity and requires decision makers to search for innovative methodologies and technological tools. Today, vehicle routing is one of the highest logistics knowledge demand areas in the region. Other challenges that have been growing in Latin American cities include food distribution to areas of the city where disadvantaged population resides.

As stated by Ruiz-Torres et al. (2012) logistics problems in Latin America are abundant and complex, however "Latin America is now a large potential market" (Blanco and Paiva, 2014). Therefore, it is important to identify logistics systems that have been successful in the region. One of the key elements in the success of global companies running operations in Latin America is the development of a specific local approach when designing and executing their logistics (Branco et al., 2014). To do this, local and global companies need human resources with high logistics knowledge and competences when designing the "local footprint" in best practices that have been proven in developed markets. This would be the first step in the design of logistics systems that respond directly to the local reality. Thus, local logistics knowledge management is already critical to succeed.

Logistics knowledge is not only important to increase commercial competiveness, but it is critical during disruptive events, such as natural disasters that have recently been occurring with higher frequency. The relevance of having systems and people that can react in a coordinated way in emergency situations is extremely important. The September 2017 earthquakes in Mexico, flooding and infrastructure disruptions caused by hurricanes in Puerto Rico and Houston underscore the importance of having a coordination framework for a reliable aid distribution. This is no longer an option for private sector companies, government agencies and the society.

Under this context, this Special Issue of the Journal of Industrial Engineering and Management (JIEM) gathers nine significant contributions, which from a Latin American approach, enhance the logistics systems body of knowledge focused on emerging markets.

\section{Overview of Selected Papers}

Nine papers were selected for this issue based on their technical quality, originality and connection with the call for papers of this Special Issue. The papers were grouped in five categories: i) Manufacturing Systems; ii) Vehicle Routing Problems; iii) Food Supply Chains; iv) Supply chain Knowledge Management; and v) Humanitarian Supply Chains. 
First, in the Manufacturing Systems category, two papers were selected for their balanced technicalpractical contribution to the logistics body of knowledge. Second, three papers in the Vehicle Routing category present interesting methodological approaches to solve one of the current key challenges in Latin America. Guarantying food supplies in time and form to the population in need was the subject of one of the papers in the third category. Another one identifies how the structure affects logistical performance in the supply chains of perishable foods. The role of knowledge management in supply chain management through a literature review is analyzed in the fourth category. Finally, in the fifth category, an inspiring article proposes a methodology to minimize the impact of a lack of coordination on humanitarian logistics decisions.

Under the Manufacturing Systems category, an article by Pinto-Junior and Veiga-Mendes proves the relationship between lean manufacturing operations and the reduction of environmental impacts. The authors first have a theoretical validation through an extensive literature review, followed by exploratory research in an electronics industry company. The important level of savings proves the proposed approach. A second paper in this category by Cedillo-Campos, Morones Ruelas, Lizarraga-Lizarraga, Gonzalez-Feliu and Garza-Reyes, researches an important topic for which there is a lack of literature, the optimization of sequential deliveries. The authors analyzed and prove the advantages of Just-In-Sequence systems, when manufacturing companies and third-party logistics firms are looking for controlling costs due to product variety management, and reducing the risk of disruption in sourcing.

In the Vehicle Routing category, Velarde-Cantú, Bueno Solano, Lagarda Leyva and Lopez Acosta researched the challenge of optimizing territories and transport routes for hazardous materials in a distribution network. A mathematical optimization model in mixed integer linear programming is proposed. The model reports a quick and efficient solution, which provides the process manager with enough information to optimize the use of the distribution resources. Another interesting article in this category from Garzón-Garnica, Caballero-Morales and Martínez-Flores, presents a model to solve large scale personnel transport systems applied in the City of Puebla, in Mexico. The authors used a metaheuristic algorithm with real transit time information from Puebla. The model could be applied in other Latin American cities with the same characteristics. Finally, in this category, Bernal, Escobar and Linfati, propose a novel two-phase heuristics algorithm that uses a granular tabu search to improve the final solution. Authors developed computational experiments on real instances to achieve a high-quality solution.

The Food Supply category includes a paper from Cuevas-Ortuño and Gomez-Padilla that presents how a food bank recovers food near its expiration date from large grocery stores distribution networks to distribute to population in need. A new problem of linear-mixed programming model for the allocationpacking of multiple pantries, personalized for food banks considering the opinion of the decision maker in 
the selection of the best solution is presented. Development of a logistics system that could collect food near expiration as soon as the donor send the alert is the first step, followed by the development of a distribution system that facilitates food delivery to families in need in the shortest possible time. Also, Orjuela-Castro and Adarme-Jaimes, researched how the structure affects logistical performance and how food security is critical in the supply chains of perishable foods (SCPF). The authors proposed an innovative system dynamics model to analyze the effects of structures: lean, agile, flexible, responsive and resilient, in the overall performance and of each agent of the SCPF.

Pérez-Salazar, Aguilar Lasserre, Cedillo-Campos and Hernández González, studied the state of knowledge management research in supply chain management from three perspectives: i) Methods; ii) Supply chain; and iii) knowledge management. Their findings showed that knowledge management plays an important role in supporting the implementation of supply chain management practices. Considering the importance of supply chain knowledge to deal with new challenges in Latin America, this article is an important element to establish better logistic development strategies for private companies and countries in the region.

Under the Humanitarian Supply Chains category, Regis-Hernández, Mora-Vargas and Ruíz proposed a methodology that translates multiple humanitarian supply chain stakeholders' preferences from qualitative to quantitative values. Thanks to this approach, these preferences can be integrated into optimization models to guarantee their well-adjustment when taking decisions under uncertainty.

It is important to note that the selected articles of this Special Edition are only a sample of the great opportunities that exist for research and practice in the Latin American region. However, these papers are representative of relevant aspects in the effective design of logistics systems in the region. Within this logistics complexity lies the opportunity that this Special Edition attempts to motivate for the development of endogenous practical and theoretical solutions. Practical solutions that contribute to improving competitiveness in the region, as well as theoretical solutions that increase the body of logistics systems knowledge in emerging markets.

\section{References}

Anderson, B. \& Villa, J-C (2015). Transportation and trade across international borders. Research in Transportation Business \& Management, 16(September), 1-3. https://doi.org/10.1016/j.rtbm.2015.08.005

BBVA Research (2017). Urbanización en América Latina. Mexico. 
Blanco, E., \& Paiva, L. (2014). Supply chain management in Latin America. International Journal of Physical Distribution \& Logistics Management, 44(7).

Blyde, J. (2014). Fábricas sincronizadas: América Latina y el Caribe en la era de las Cadenas Globales de Valor. Banco Inter-Americano de Desarrollo. Washington, EE.UU.

Branco, J., Cabral, L., Kraiselburd, S., Silva, I., \& Witty, T. (2014). Building a winning supply chain in Latin America. CSCMP's Supply Chain Quarterly, 40-47.

Capurro, D. (2017). Donald Trump's trade policy is driving Latin America into China's arms. The Telegraph. London, England.

Cedillo-Campos, M., Sanchez, C., Vadali, S., Villa, J., \& Menezes, M. (2014). Supply chain dynamics and the "cross-border effect:" The U.S.-Mexican border's case. Computers and Industrial Engineering, 72, 261273. https://doi.org/10.1016/j.cie.2014.03.015

IDB - Inter-American Development Bank (2017). Logistics Costs. Available on-line at: http://logisticsportal.iadb.org/node/2019

The Economist (2016). Latin America and China: A golden opportunity. London, England.

Ruiz-Torres, A., Mahmoodi, F., \& Ayala-Cruz, J. (2012). Supply Chain Management Research in Latin America: A Review. Supply Chain Forum: An International Journal, 13(1), 20-36.

Journal of Industrial Engineering and Management, 2017 (www.jiem.org)

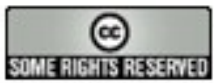

Article's contents are provided on an Attribution-Non Commercial 3.0 Creative commons license. Readers are allowed to copy, distribute and communicate article's contents, provided the author's and Journal of Industrial Engineering and Management's names are included. It must not be used for commercial purposes. To see the complete license contents, please visit http://creativecommons.org/licenses/by-nc/3.0/. 